\title{
¿DERECHO A LA CASACIÓN? LECTURA A CONTRACORRIENTE DE LA JURISPRUDENCIA DEL TRIBUNAL CONSTITUCIONAL
}

\author{
Williams Eduardo Valenzuela Villalobos* \\ Universidad Mayor-Chile \\ williams.valenzuela@umayor.cl
}

\section{Sentencias del Tribunal Constitucional \\ i. Resumen sentencia Rol No 2529-13 de 2 de enero de 2015}

Santiago, dos de enero de dos mil quince.

VISTOS:

Con fecha 23 de septiembre de 2013, Inversiones Hoteles de Chile S.A. ha requerido a este Tribunal la declaración de inaplicabilidad por inconstitucionalidad del inciso segundo del artículo 768 del Código de Procedimiento Civil, por vulnerar las garantías del artículo 19 , numerales $2^{\circ}$ y $3^{\circ}$, de la Constitución Política de la República.

\section{CONSIDERANDO:}

\section{Cuestión de constitucionalidad.}

Primero: Que el presente caso plantea la cuestión de si se justifica que en los procesos tributarios no rijan en plenitud las causales que en los juicios ordinarios hacen procedente el recurso de casación. Más precisamente, si -de frente a la igualdad ante la justicia- tiene validez constitucional que en dichos conflictos se aplique la excepción del inciso segundo del artículo 768 del Código de Procedimiento Civil, cuyo enunciado normativo - para lo que aquí interesa- puede describirse así:

En los juicios o reclamaciones regidos por leyes especiales, no se admite el recurso de casación en la forma contra una sentencia que ha omitido las consideraciones de hecho o de derecho que le sirven de fundamento, o que se ha

* Licenciado en Ciencias Jurídicas, Abogado. Magíster en Derecho Constitucional y Derechos Humanos de la Universidad de Talca. Profesor Asociado de Derecho Procesal de la Universidad Mayor, Santiago. 
dictado faltado un trámite o diligencia tan esencial como es la previa recepción de la causa a prueba;

Segundo: Que precisamente la presente inaplicabilidad se solicita porque en el fallo expedido por el Director Regional del Servicio de Impuestos Internos como juez tributario (fs. 45-50) no se ponderó cierta evidencia presentada en su reclamación por el contribuyente (fs. 217-266), al no recibirse inmotivadamente la causa a prueba respecto al punto en disputa singularizado como "concepto 1" y en que esa evidencia incidía (fs. 41). La sentencia de segunda instancia (fs. 5152) confirmó sin modificaciones la de primer grado, faltándole los requisitos del inciso segundo del artículo 170 del Código de Procedimiento Civil, además de no examinar -ni menos remediar- aquellos vicios de forma que esta presentaría, según requiere el artículo 140 del Código Tributario.

La evidencia presentada, pero no considerada en definitiva, sería determinante para elucidar cuál empresa -entre dos relacionadas en el caso- soportó en los hechos ciertos costos, a los efectos posteriores de poder ser calificados como gastos necesarios para producir renta, todo lo cual repercute en la exacta aplicación de la legislación tributaria pertinente;

Tercero: Que no compete a este Tribunal determinar si en el aludido proceso tributario hubo o pudo haber controversia sobre aquel hecho sustancial y pertinente; tampoco si a su respecto debió o no recibirse la causa a prueba; ni está en sus manos enjuiciar si la prueba acompañada debió ponderarse en definitiva. Menos puede especular si el veredicto de fondo omitió decidir sobre el asunto controvertido. Así como le está vedado opinar si cabe una casación para ante la Corte Suprema, en el estado actual de la gestión judicial pendiente.

En cambio, entra en sus atribuciones pronunciarse acerca de la excepción que la ley adjetiva civil hace en este tipo de contenciosos, en cuya virtud a los justiciables se les niega el acceso a un recurso de casación en la forma donde se puedan revisar esas presuntas infracciones, amén de no concederles una equivalente vía de impugnación en su reemplazo.

\section{Antecedentes.}

Cuarto: Que, desde luego, la legislación no permite que en las sentencias recaídas en los juicios especiales se excluyan sus motivaciones, ni faculta emitirlas prescindiendo de formalidades sustanciales de esa índole. Lo anterior, por cuanto el mismo Código requiere dichas razones de hecho y de derecho en las disposiciones comunes a todo procedimiento (artículo 170, No 4), a la vez que identifica como un trámite o diligencia esencial-incluso en los juicios especiales- el recibimiento de la causa a prueba (artículo 795, No 3). 
Mas, lo objetable es que la ausencia de un recurso anulatorio efectivo en tal orden de exigencias arriesga dejar indemnes algunas de esas infracciones, con menoscabo injustificado de los contribuyentes y del interés público comprometido, consistente en la igual defensa legal de los derechos e intereses de las partes respecto a la correcta liquidación de los impuestos adeudados;

Quinto: Que en sentencias roles $\mathrm{N}^{\circ}$ s. 1373 y 1873 esta Magistratura declaró que el inciso segundo del artículo 768, controvertido, infringe la garantía de igualdad ante la ley procesal, recogida en los números $2^{\circ}$ y $3^{\circ}$ del artículo 19 constitucional, dado que -discriminatoriamente- niega a unos justiciables, por solo quedar afectos a procesos especiales, el mismo recurso de interés general del cual disponen todos quienes están sujetos al juicio ordinario. En circunstancias que se trata de casar sentencias que padecen idénticos vicios, como son el haber omitido la recepción de la causa a prueba y los fundamentos que les sirven de sostén.

Se dijo asimismo allí que no se advierte claramente una finalidad intrínsecamente legítima en el precepto cuestionado, al impedir que los fallos recaídos en los juicios regidos por leyes especiales puedan ser objeto de casación por las causales anotadas. "Ningún fundamento racional aparece en la citada restricción y no se divisa la razón para privar al litigante de un juicio determinado del mismo derecho que le asiste a cualquier otro en la generalidad de los asuntos" (Rol No 1373 , considerando $19^{\circ}$ ).

Tanto como se consideró que dicha norma quebranta el derecho a un juicio justo y racional, al privar al afectado por una sentencia así viciada del instrumento normal llamado a corregir el vicio, amén de no contemplar otra vía de impugnación que asegure un debido proceso y la concesión de tutela judicial efectiva (Rol No 1373, considerandos 13 y 17).

\section{Igualdad ante la ley.}

Sexto: Que, reiterada aquella jurisprudencia precitada, cabe agregar que respecto de la exclusión cuestionada no se encuentra explicación alguna en los anales de su consagración. En efecto, el texto original del Código de Procedimiento Civil, de 1902, no formuló distinción alguna, concediendo el recurso de casación "en jeneral" contra toda sentencia definitiva (artículo 939, actual 766), incluso por las causales que aquí interesan (artículo 941, actual 768).

Fue la ley No 3.390, del año 1918, la que incorporó aquel inciso que excluye el recurso de casación contra las sentencias que, en los negocios que se tramitan como juicios especiales, omiten sus fundamentos de hecho y de derecho, o se despachan sin cumplir con aquellos trámites o diligencias que la ley considera esenciales (artículo 941, 768 actual). Consultada la historia de su establecimiento, aparece 
que esta norma se propuso en el Senado con fecha 26 de febrero de 1915, sin que a su respecto se produjera debate o se aportara alguna explícita razón (página 41);

Séptimo: Que, en todo caso, la excepción que impide casar una sentencia inmotivada o que ha incumplido las reglas de un debido proceso legal, es obvio que estaba ideada para operar en casos asimismo excepcionales. Esto, porque a la sazón la regla general y situación habitual era que los juicios se ventilaran conforme al procedimiento ordinario, con una "tramitación común ordenada por la ley", siendo "extraordinario" el procedimiento "que se rige por las disposiciones especiales que en determinados casos ella establece", según la concepción del artículo $2^{\circ}$ del mismo Código de Procedimiento Civil.

Sin embargo, con posterioridad, sucesivas leyes han dispuesto que una gran variedad de controversias se sustancien conforme a diversos procedimientos especiales, para la pronta y cumplida administración de justicia e inspiradas en el sano designio de suprimir o agilizar los trámites más dilatados y engorrosos de un juicio de lato conocimiento u ordinario. Pero de ello no se sigue un necesario menoscabo, ni cabe suponer la existencia de algún móvil deliberado merced al cual, en los juicios especiales, deberían excluirse los recursos de nulidad o quedar coartado el acceso a la casación;

Octavo: Que ningún propósito jurídico permite hacer más severo, por una aplicación demasiado dura y contra el interés de las personas, aquello que ha sido introducido saludablemente para la utilidad de las mismas y el mejor funcionamiento de las instituciones (Digesto 1.3.25).

Por caso, y comoquiera que el establecimiento de juicios especiales es compatible -aun inmanente- con la plena procedencia del recurso de casación, la ley No 19.968 tuvo cuidado de acogerlo en los procesos que se ventilan ante los Tribunales de Familia, por algunas de las causales que prevé el artículo 768 del Código de Procedimiento Civil, incluso cuando la sentencia definitiva ha eludido diligencias esenciales o aparece desprovista de causas jurídicas o de hecho (artículos 66 y 67, No 6, letra b). La ley No 20.600, igualmente, dispone que los fallos de los Tribunales Ambientales deben satisfacer los requisitos del artículo 170 del Código de Procedimiento Civil y que son susceptibles del recurso de casación en la forma para ante la Corte Suprema, especialmente cuando no enuncian los fundamentos con arreglo a los cuales se pronuncian (artículos 25 y 26, inciso cuarto);

Noveno: Que, por las razones antedichas, no se admitirá la alegación planteada por la defensa del Estado (fs. 198) y por el Servicio de Impuestos Internos (fs. 454) de que el impedimento para deducir una casación se aplica por igual a ambas partes del proceso tributario. 
Menos cuando la situación, que se desea someter a la superior consideración de la Corte Suprema, tiene su origen en un procedimiento tramitado en sede administrativa, según la antigua justicia tributaria donde la autoridad administrativa oficiaba de juez y parte. En el cual, sin tenerse en cuenta la prueba acompañada por la requirente, aparece que un informe de fiscalización expedido por el propio Servicio de Impuestos Internos (fs. 323) fue incorporado al expediente (fs. 329) y considerado en el fallo de primera instancia como elemento de juicio determinante respecto a los hechos involucrados y su calificación jurídica, según la plena coincidencia que se observa entre este veredicto y aquel acto administrativo, ambos provenientes del mismo servicio indicado (fs. 48 y 326).

\section{Justicia Tributaria.}

Décimo: Que, por otra parte, para justificar la exclusión hecha por el inciso segundo del artículo 768 de la ley procesal civil, no puede admitirse el argumento de que en los negocios tributarios ello armonizaría "con la condición de los Directores Regionales del Servicio de Impuestos Internos, quienes no necesariamente son abogados, y no poseen la preparación de los jueces que detentan dicha profesión, dentro de lo cual probablemente no conocen todas las ritualidades del proceso" (fs. 452 vta.).

$\mathrm{Al}$ contrario, el que previo a las reformas introducidas en la materia por la ley No 20.322 tales directores administrativos ejercieran como jueces tributarios, sin ser abogados, podría respaldar la plena procedencia del recurso de casación en la forma, con el objeto justamente de resguardar la indemnidad de aquellos trámites y diligencias que la ley considera esenciales en todo tipo de juicios y sin exclusiones. Además que su experticia, lo que en el pasado explicó que se les depositara jurisdicción en esta clase de contenciosos, sugeriría más bien disponerlos a rendir cuenta razonada de sus fallos;

Decimoprimero: Que el artículo 140 del Código Tributario dispone: "En contra de la sentencia de primera instancia no procederá el recurso de casación en la forma ni su anulación de oficio. Los vicios en que se hubiere incurrido deberán ser corregidos por el Tribunal de Apelaciones que corresponda".

Dicha norma escatima la casación contra el fallo de primer grado, en la confianza de que el órgano de apelación habrá de enmendar los defectos aludidos. Es lo cierto, sin embargo, que ella no hace referencia a la casación contra la sentencia de segunda instancia, para el evento de que ese tribunal no actúe como está previsto y reproduzca en su sentencia los mismos vicios de que adolece el fallo de primer grado. Vale decir, una sentencia estimatoria puede tener influencia decisiva; 
Decimosegundo: Que, así las cosas, la excepción del inciso segundo del artículo 768 del Código de Procedimiento Civil no condice con el imperativo que le asiste al legislador, por mandato de la Constitución (artículo 19, o 3o), de allanar el acceso a un recurso útil en las circunstancias anotadas, motivo por el cual el presente requerimiento se acogerá.

Teniendo además en cuenta el criterio sostenido en diversas ocasiones por este Tribunal, en orden a que los preceptos de excepción contenidos en una ley, en cuanto sustraen de cierta normativa general a personas o situaciones determinadas, produciéndoles menoscabo y sin fundamento o justificación, importan la comisión de diferencias arbitrarias y son, por ende, contrarias a la Constitución (artículo 19, No $2^{\circ}$, inciso segundo), como en este caso ocurre;

Decimotercero: Que, por último, conviene prevenir que al acoger el presente requerimiento, el Tribunal Constitucional no está creando un recurso inexistente, puesto que -en lógica- al eliminarse una excepción solo retoma vigencia la regla. Cual es que la casación se abre para la totalidad de los mismos casos e idénticas causales en que está llamada a regir, sin exclusión, según la preceptiva vigente.

Tampoco esta sentencia estimatoria implica desconocer el carácter extraordinario que reviste la casación, dado que se limita a entender que no se justifica excluirla respecto de las mismas sentencias y por iguales motivos a aquellos que permiten su interposición según la normativa imperante.

$Y$ Teniendo Presente lo preceptuado en los artículos 19 , numerales $2^{\circ}$ y $3^{\circ}$, y 93, incisos primero, $\mathrm{N}^{\circ} 6^{\circ}$, y decimoprimero, de la Carta Fundamental, así como en las disposiciones pertinentes de la ley No 17.997, Orgánica Constitucional del Tribunal Constitucional,

Se resuelve:

Que se acoge el requerimiento deducido y, en consecuencia, se declara inaplicable el inciso segundo del artículo 768 del código de procedimiento civil.

Déjase sin efecto la suspensión del procedimiento decretada a fojas 84, debiendo oficiarse al efecto.

Acordada con el voto en contra de los Ministros señores Carlos Carmona Santander, Marisol Peña Torres, Francisco Fernández Fredes y Domingo Hernández Emparanza, quienes estuvieron por rechazar el requerimiento, fundados en las siguientes razones:

Redactó la sentencia el Ministro señor Iván Aróstica Maldonado y la disidencia, el Ministro señor Carlos Carmona Santander.

Notifíquese, comuníquese, regístrese y archívese.

Rol No 2529-13-INA. 
Pronunciada por el Excmo. Tribunal Constitucional, integrado por su Presidente, Ministro señor Carlos Carmona Santander, la Ministra señora Marisol Peña Torres, los Ministros señores Raúl Bertelsen Repetto, Hernán Vodanovic Schnake, Francisco Fernández Fredes, Iván Aróstica Maldonado, Domingo Hernández Emparanza, Juan José Romero Guzmán y la Ministra señora María Luisa Brahm Barril.

Autoriza la Secretaria del Tribunal Constitucional, señora Marta de la Fuente Olguín.

\section{ii. Resumen sentencia Rol No 2677-14 de 4 de junio de 2015}

Santiago, cuatro de junio de dos mil quince.

\section{VISTOS:}

Con fecha 18 de junio de 2014, la Sociedad Plasma Limitada ha solicitado la declaración de inaplicabilidad por inconstitucionalidad del inciso segundo del artículo 768 del Código de Procedimiento Civil, para que surta efectos en el proceso sobre casación en la forma y en el fondo, sustanciado por la Corte Suprema bajo el Rol No 11319-14.

\section{CONSIDERANDO:}

\section{Cuestión de constitucionalidad.}

Primero: Que el presente caso plantea la cuestión de si se justifica que en los procedimientos motivados por arrendamiento de predios urbanos no rijan en plenitud las causales que en los juicios ordinarios hacen procedente el recurso de casación en la forma. Más precisamente, si -de frente a la igualdad ante la justicia- tiene validez constitucional que en dichos conflictos se aplique la excepción del inciso segundo del artículo 768 del Código de Procedimiento Civil, cuyo enunciado normativo - para lo que aquí interesa- puede describirse así: en los juicios o reclamaciones regidos por leyes especiales, no se admite el recurso de casación en la forma contra una sentencia que ha omitido las consideraciones de hecho o de derecho que le sirven de fundamento;

Segundo: Que la descrita prohibición no se aviene con el derecho que tienen todas las partes de acceder al recurso de que se trata. De igual modo, la ablación del recurso de casación en la forma impide que la Corte Suprema pueda unificar la aplicación de toda norma de rango legal, sea esta de carácter sustantivo o procesal.

Razones ambas por las cuales este Tribunal decidirá que el inciso segundo del artículo 768 del Código de Procedimiento Civil, en su aplicación a la gestión pendiente, es inaplicable por inconstitucional; 
Tercero: Que la inaplicabilidad se pide puesto que la sentencia de la Corte de Apelaciones de Santiago (fs. 166-175), al acoger un recurso de apelación en contra de la sentencia emitida por el 6o Juzgado Civil de Santiago (fs. 101-164), se expidió sin expresar por qué eliminó algunas de las consideraciones de esta.

Las motivaciones eliminadas por la Corte de Apelaciones, sin fundamento, serían determinantes puesto que dan cuenta de hechos y a la sazón de su calificación jurídica, sobre los que el Juzgado Civil rechazó dar por terminado un contrato de arriendo, y por los cuales optó por declarar su desahucio. Por lo anterior la requirente de autos interpuso recurso de casación en la forma, motivada, en lo pertinente, en la infracción del artículo 768 del Código de Procedimiento Civil, en cuanto a su causal $5^{a}$, debido a que la sentencia de alzada no tendría "consideraciones de hecho o de derecho que sirvan de fundamento a la sentencia" (artículo 170, No 4, del Código de Procedimiento Civil);

Cuarto: Que no compete a este Tribunal determinar cuáles son los hechos y el derecho aplicables en el aludido proceso civil, así como le está vedado opinar si cabe una casación para ante la Corte Suprema, en el estado actual de la gestión judicial pendiente.

En cambio, entra en sus atribuciones pronunciarse acerca de la excepción que la ley adjetiva civil hace en este tipo de contenciosos, en cuya virtud a los justiciables se les niega el acceso a un recurso de casación, amén de no concederles una equivalente vía de impugnación en su reemplazo.

\section{Antecedentes.}

Quinto: Que, desde luego, la legislación no permite que en las sentencias recaídas en los juicios especiales se excluyan sus motivaciones, ni faculta emitirlas prescindiendo de formalidades sustanciales de esa índole. Lo anterior, por cuanto el mismo Código requiere dichas razones de hecho y de derecho en las disposiciones comunes a todo procedimiento (artículo 170, No 4).

Mas lo objetable es que la ausencia de un recurso anulatorio efectivo en tal orden de exigencias arriesga dejar indemnes algunas de esas infracciones, con menoscabo injustificado de las partes y del interés público comprometido, consistente en la igual defensa legal de los derechos e intereses de los litigantes;

Sexto: Que en sentencias roles $\mathrm{No}^{\circ}$. 1373, 1873 y 2529 esta Magistratura declaró que el inciso segundo del artículo 768 , controvertido, infringe la garantía de igualdad ante la ley procesal, recogida en los números $2^{\circ}$ y $3^{\circ}$ del artículo 19 constitucional, dado que -discriminatoriamente- niega a unos justiciables, por solo quedar afectos a procesos especiales, el mismo recurso de interés general del cual disponen todos quienes están sujetos al juicio ordinario. En circunstancias 
que se trata de casar sentencias que padecen idénticos vicios, como lo es el haber omitido los fundamentos que les sirven de sostén.

Se dijo asimismo allí que no se advierte claramente una finalidad intrínsecamente legítima en el precepto cuestionado, al impedir que los fallos recaídos en los juicios regidos por leyes especiales puedan ser objeto de casación por las causales anotadas. "Ningún fundamento racional aparece en la citada restricción y no se divisa la razón para privar al litigante de un juicio determinado del mismo derecho que le asiste a cualquier otro en la generalidad de los asuntos" (Rol No 1373, considerando 19).

Tanto como se consideró que dicha norma quebranta el derecho a un juicio justo y racional, al privar al afectado por una sentencia así viciada del instrumento normal llamado a corregir el vicio, amén de no contemplar otra vía de impugnación que asegure un debido proceso y la concesión de tutela judicial efectiva (Rol No 1373, considerandos 13 y 17).

Igualdad ante la ley.

Séptimo: Que, reiterada aquella jurisprudencia precitada, cabe agregar que no es lo mismo la consagración de normas especiales que el establecimiento de normas excepcionales.

Porque en el primer caso, como sucede con los juicios especiales, en lo no previsto por las disposiciones particulares, rigen las normas generales o comunes, habida cuenta que entre ambas no existe oposición en cuanto a los principios rectores involucrados. Mientras que en el segundo caso, tratándose de normas excepcionales, ellas rechazan precisamente la aplicación de las reglas generales o comunes, por una razón concreta que amerita la exclusión.

Admitido, pues, que los juicios de arriendo poseen peculiaridades tales que justifican una normativa procesal especial, el caso es que no se encuentra fundamento cuando la ley -el artículo 768 cuestionado- consagra a su respecto una excepción;

Octavo: Que, en efecto, respecto de la exclusión cuestionada, no se encuentra explicación alguna en los anales de su consagración. El texto original del Código de Procedimiento Civil, de 1902, no formuló distinción alguna, concediendo el recurso de casación "en jeneral" contra toda sentencia definitiva (artículo 939, actual 766), incluso por las causales que aquí interesan (artículo 941, actual 768).

Fue la ley No 3.390, del año 1918, la que incorporó aquel inciso que excluye el recurso de casación contra las sentencias que, en los negocios que se tramitan como juicios especiales, omiten sus fundamentos de hecho y de derecho, o se despachan sin cumplir con aquellos trámites o diligencias que la ley considera esenciales 
(artículo 941, 768 actual). Consultada la historia de su establecimiento, aparece que esta norma se propuso en el Senado con fecha 26 de febrero de 1915, sin que a su respecto se produjera debate o se aportara alguna explícita razón (página 41);

Noveno: Que, en todo caso, la excepción que impide casar una sentencia inmotivada o que ha incumplido las reglas de un debido proceso legal, es obvio que estaba ideada para operar en casos asimismo excepcionales. Esto, porque a la sazón la regla general y situación habitual era que los juicios se ventilaran conforme al procedimiento ordinario, con una "tramitación común ordenada por la ley", siendo "extraordinario" el procedimiento "que se rige por las disposiciones especiales que en determinados casos ella establece”, según la concepción del artículo $2^{\circ}$ del mismo Código de Procedimiento Civil.

Sin embargo, con posterioridad, sucesivas leyes han dispuesto que una gran variedad de controversias se sustancien conforme a diversos procedimientos especiales, para la pronta y cumplida administración de justicia e inspiradas en el sano designio de suprimir o agilizar los trámites más dilatados y engorrosos de un juicio de lato conocimiento u ordinario. Pero de ello no se sigue un necesario menoscabo, ni cabe suponer la existencia de algún móvil deliberado merced al cual, en los juicios especiales, deberían excluirse los recursos de nulidad o quedar coartado el acceso a la casación en la forma;

Décimo: Que ningún propósito jurídico permite hacer más severo, por una aplicación demasiado dura y contra el interés de las personas, aquello que ha sido introducido saludablemente para la utilidad de las mismas y el mejor funcionamiento de las instituciones (Digesto 1.3.25).

Por caso, y comoquiera que el establecimiento de juicios especiales es compatible -aun inmanente- con la plena procedencia del recurso de casación, la ley No 19.968 tuvo cuidado de acogerlo en los procesos que se ventilan ante los Tribunales de Familia, por algunas de las causales que prevé el artículo 768 del Código de Procedimiento Civil, incluso cuando la sentencia aparece desprovista de causas jurídicas o de hecho (artículos 66 y 67, No 6, letra b)). La ley No 20.600, igualmente, dispone que los fallos de los Tribunales Ambientales deben satisfacer los requisitos del artículo 170 del Código de Procedimiento Civil y que son susceptibles del recurso de casación en la forma para ante la Corte Suprema, especialmente cuando no enuncian los fundamentos con arreglo a los cuales se pronuncian (artículos 25 y 26, inciso cuarto);

Decimoprimero: Que, así las cosas, la excepción del inciso segundo del artículo 768 del Código de Procedimiento Civil no condice con el imperativo que le asiste al legislador, por mandato de la Constitución (artículo 19, No 3o), de allanar 
el acceso a un recurso útil en las circunstancias anotadas, motivo por el cual el presente requerimiento se acogerá.

Teniendo además en cuenta el criterio sostenido en diversas ocasiones por este Tribunal, en orden a que los preceptos de excepción contenidos en una ley, en cuanto sustraen de cierta normativa general a personas o situaciones determinadas, produciéndoles menoscabo y sin fundamento o justificación, importan la comisión de diferencias arbitrarias y son, por ende, contrarias a la Constitución (artículo 19, No 2o, inciso segundo), como en este caso ocurre;

Decimosegundo: Que, por último, conviene prevenir que al acoger el presente requerimiento, el Tribunal Constitucional no está creando un recurso inexistente, puesto que -en lógica- al eliminarse una excepción solo retoma vigencia la regla. Cual es que la casación se abre para la totalidad de los mismos casos e idénticas causales en que está llamada a regir, sin exclusión, según la preceptiva vigente.

Tampoco esta sentencia estimatoria implica desconocer el carácter extraordinario que reviste la casación, dado que se limita a entender que no se justifica excluirla respecto de las mismas sentencias y por iguales motivos a aquellos que permiten su interposición según la normativa imperante.

$Y$ teniendo presente lo preceptuado en los artículos 19 , numerales $2^{\circ}$ y $3^{\circ}, y$ 93, incisos primero, No $^{\circ}$, y decimoprimero, de la Carta Fundamental, así como en las disposiciones pertinentes de la Ley No 17.997, Orgánica Constitucional del Tribunal Constitucional,

Se resuelve:

Que se acoge el requerimiento deducido y, en consecuencia, se declara inaplicable el inciso segundo del artículo 768 del Código de Procedimiento Civil.

Déjase sin efecto la suspensión del procedimiento decretada a fojas 295 , debiendo oficiarse al efecto.

Acordada con el voto en contra de los Ministros señores Carlos Carmona Santander, Presidente, Marisol Peña Torres, Gonzalo García Pino y Domingo Hernández Emparanza, quienes estuvieron por rechazar el presente requerimiento, fundados en las siguientes razones:

Redactó la sentencia el Ministro señor Iván Aróstica Maldonado y la disidencia, el Ministro señor Carlos Carmona Santander.

Notifíquese, regístrese y archívese.

Rol No 2677-14-INA.

Pronunciada por el Excmo. Tribunal Constitucional, integrado por su Presidente, Ministro señor Carlos Carmona Santander, y por los Ministros señora Marisol Peña Torres, señores Raúl Bertelsen Repetto, Hernán Vodanovic Schnake, Iván 
Aróstica Maldonado, Gonzalo García Pino, Domingo Hernández Emparanza, Juan José Romero Guzmán y señora María Luisa Brahm Barril.

Se certifica que los Ministros señores Raúl Bertelsen Repetto y Hernán Vodanovic Schnake concurrieron al acuerdo, pero no firman por haber cesado en sus cargos.

Autoriza la Secretaria del Tribunal Constitucional, señora Marta de la Fuente Olguín.

\section{COMENTARio}

Los fallos anteriores sirven de excusa para discurrir sobre la jurisprudencia, reciente e histórica, que ha desarrollado el Tribunal Constitucional en materia de derecho al recurso y, asimismo, permiten analizar una suerte de extralimitación de los alcances constitucionales previstos para la declaración de inaplicabilidad.

Como premisa, podemos señalar que el derecho a recurrir o a impugnar las resoluciones judiciales forma parte de las garantías del debido proceso, mas, como derecho fundamental, es necesario delimitar su contenido y alcance, es decir, aquello que le es consustancial y que forma parte del haz de garantías protegidas.

Lo anterior cobra importancia, en la medida que la Magistratura Constitucional ha venido consolidando una jurisprudencia que amplía el contenido asegurado por el derecho, haciendo parte del debido proceso la posibilidad de revisión extraordinaria, por medio de recursos procesales de derecho estricto, como es el caso del recurso de casación.

El efecto negativo de la inaplicabilidad se ve superado en los hechos al permitir -como se verá- el acceso a un recurso procesal determinado en el marco de procedimientos, respecto de los cuales el legislador no previó su procedencia; excepción que es plenamente conforme a la Constitución.

De esta manera, el presente comentario se estructura sobre la base de cinco ejes: comenzando por establecer la naturaleza de garantía que comportan hoy los recursos procesales; luego, se analiza la delimitación del derecho al recurso; en tercer orden, se determina el origen y función del recurso de casación; en seguida, se discurre sobre los argumentos contenidos en los fallos comentados y, finalmente, se hace referencia a la jurisprudencia histórica del Tribunal Constitucional en materia del derecho al recurso.

\section{A. Recursos procesales como garantía del justiciable}

El origen histórico de los recursos procesales dista mucho de la forma en que estos son concebidos en la actualidad. En sus concepciones primarias, eran en- 
tendidos como meros mecanismos de control jerárquico, propios de la estructura piramidal de la administración de justicia, donde el tribunal a quo le devolvía la competencia al ad quem a efectos de verificar su actuación. Se entendía que su establecimiento y procedencia obedecían a cuestiones de técnica legislativa, no formando parte de aquellas piezas que eran consustanciales al debido proceso.

Hoy, producto de la evolución de la ciencia procesal y del desarrollo del derecho internacional de los derechos humanos, son concebidos como garantías del justiciable frente al posible error judicial, ya que lo que subyace a su necesario establecimiento es "la posibilidad de obtener una respuesta del órgano jurisdiccional correcta, de calidad, efectiva y oportuna en pleno respeto de los derechos, valores y principios en juego" , por ello "la voluntad subyacente a la instauración de varios grados de jurisdicción significa reforzar la protección del justiciable" 2 debido a que "toda resolución es fruto del acto humano, y que por lo tanto, puede contener errores o generar distintas interpretaciones, ya sea en la determinación de los hechos o en la aplicación del derecho"3.

El derecho al recurso encuentra pleno reconocimiento a nivel convencional, tanto en el artículo 8.2.h. $-^{4}$ de la Convención Americana de Derechos Humanos, como en el artículo 14.5.-5 del Pacto Internacional de Derechos Civiles y Políticos.

En nuestro medio, existe consenso, tanto en la jurisprudencia constitucional como en la de la Excma. Corte Suprema, que tal derecho forma parte de las garantías del debido proceso constitucional, que se desprenden de lo dispuesto en el artículo 19 No 3 de la Constitución. En efecto, la Corte Suprema ha señalado:

"Que, por otra parte, es un derecho asegurado por la Constitución Política de la República, que toda sentencia de un órgano que ejerza jurisdicción debe fundarse en un proceso previo legalmente tramitado y la misma Carta Fundamental en el inciso quinto ${ }^{6}$ del

\footnotetext{
1 Valenzuela (2015), p. 41.

2 Huerta (2003), p. 57.

3 Huerta (2003), p. 57.

4 El artículo $8^{\circ}$ (garantías judiciales) de la Convención señala, en su parte pertinente: “2. Toda persona inculpada de delito tiene derecho a que se presuma su inocencia mientras no se establezca legalmente su culpabilidad. Durante el proceso, toda persona tiene derecho, en plena igualdad, a las siguientes garantías minimas: h) derecho de recurrir del fallo ante juez o tribunal superior".

5 El artículo 14 del Pacto señala: "5. Toda persona declarada culpable de un delito tendrá derecho a que el fallo condenatorio y la pena que se le haya impuesto sean sometidos a un tribunal superior, conforme a lo prescrito por la ley".

6 Hoy inciso $6^{\circ}$.
} 
numeral $3^{\circ}$ de su artículo 19, confiere al legislador la misión de establecer siempre las garantias de un procedimiento racional y justo; en cuanto a los aspectos que comprende el derecho del debido proceso, no hay discrepancias en que, a lo menos lo conforman, el derecho de ser oido, de presentar pruebas para demostrar las pretensiones de las partes, de que la decisión sea razonada y la posibilidad de recurrir en su contra, siempre que la estime agraviante, de acuerdo a su contenido"7.

\section{B. Delimitación del derecho al recurso}

\section{El derecho al recurso asegura y protege ${ }^{8}$ :}

i. La existencia de arbitrios procesales para ante un tribunal superior ${ }^{9}$, que permitan alzarse contra las resoluciones agraviantes para el justiciable;

ii. Los arbitrios procesales son de libre configuración por los legisladores nacionales, en lo que dice relación a los plazos, requisitos formales o nomen iuris que se le atribuya a los mismo ${ }^{10}, \mathrm{y}$

7 Corte Suprema, 28 de abril de 2010, Rol No 873-10. Considerando décimo.

8 Valenzuela (2015), pp. 41-43.

9 La configuración del recurso por parte del legislador es libre, pero las exigencias del derecho al recurso no se satisfacen con la mera existencia de un tribunal superior, ya que "si el juzgamiento de segunda instancia no satisface los requerimientos del juez natural, no podrá considerarse como legitima y válida la etapa procesal que se desarrolla ante él...". Corte IDH, Caso Castillo Petruzzi y otros vs. Perú, Fondo, Reparaciones y Costas. Sentencia de 30 de mayo de 1999, Serie C No 52, párrafo 161.

10 El derecho al recurso -como toda acción que permite tener acceso a la justicia y lograr así tutelar efectivamente los derechos de la persona- posibilita (dentro de la libertad que posee el legislador) el establecimiento de requisitos para el ejercicio de los arbitrios que permitan el nuevo examen de la causa, con todo, dichos requisitos no pueden transformar en irrealizable el derecho, limitándolo desproporcionadamente e impidiendo, en definitiva, el derecho a la revisión de las sentencias y resoluciones judiciales. Es lícito al legislador limitar el acceso a los recursos, pero dichos requisitos, que siempre deben "ser interpretados en clave de derechos humanos" (Nogueira (2008), Tomo II, p. 272), no deben -al extremo- limitar más allá de lo permitido la debida tutela de los derechos de la persona humana. Así, González Pérez agrupa las siguientes características o condiciones que deben cumplir tales requisitos procesales en general, que en consecuencia son perfectamente aplicables a los recursos jurisdiccionales (GonZÁlez (2004) pp. 63 y ss.):

a) Proscripción de formalismos exagerados como requisitos procesales;

b) Que el requisito esté establecido en la ley. En Chile, al igual que el caso español, ello quedó entregado al legislador, en conformidad con el artículo 19 No $3^{\circ}$, además, por la reserva legal en materia de derechos humanos, contemplada en los artículos 19 No 26, 34 No $6^{\circ}, 63$ oo 20 y 64 de la Constitución;

c) Principio pro actione. Las fórmulas procesales deben interpretarse siempre favoreciendo la admisibilidad por sobre la declaración de inadmisibilidad, ya que el abuso de las formalidades procesales que permiten declarar la inadmisión de la acción (recursos en este caso) pueden conculcar el derecho de acceso a la justicia, transformándose en una verdadera denegación que afectaría a la tutela de los derechos, el derecho a la jurisdicción y la acción procesal misma. Señala Francisco Zúniga: “[...] asimismo, desde la perspectiva procesal el principio pro requirente debe estar situado en una perspectiva pro actione, que concibe la acción 


\section{iii. El recurso libremente configurado por el legislador debe permitir alzarse en} contra de ambos errores que puede cometer la jurisdicción: de hecho y de derecho, es decir, debe permitir un examen integral de las cuestiones fácticas, probatorias y jurídicas ${ }^{11}$, debatidas y analizadas por el tribunal inferior ${ }^{12}$, debiendo reunir el arbitrio las cualidades de ser un recurso sencillo ${ }^{13}$, ordinario ${ }^{14-15}$, eficaz ${ }^{16}$ y accesible ${ }^{17}$. Adicionalmente, y para efectos de este comentario, es dable preguntarse en qué momento el recurso que reúna dichas calidades debe estar disponible para el justiciable agraviado. Respondiendo dicha interrogante, podemos señalar:

como ' $[\ldots]$ un derecho humano a la justicia' (FIX ZAMUDIO), es decir, una garantía constitucional procesal de acceso a la tutela judicial del derecho asegurado en el artículo 19 No $3^{\circ}$ de la Constitución, y en que la acción como derecho autónomo encuentra soporte en el derecho de petición (COUTURE), derecho fundamental asegurado en el artículo 19 No 14 de la misma Carta";

d) La declaración de inadmisibilidad solo puede ser expedida por defectos procesales insubsanables, y

e) Finalmente, señala Nogueira Alcalá, que las circunstancias anteriores "son válidos no solamente en situaciones de normalidad institucionales sino también dentro de los estados de excepción constitucional". Nogueira (2008), Tomo II, P. 280.

11 Corte IDH, Caso Mohamed vs. Argentina. Excepción Preliminar, Fondo, Reparaciones y Costas. Sentencia de 23 noviembre de 2012, Serie C No 255, párrafo 100.

12 Corte IDH, Caso Herrera Ulloa vs. Costa Rica. Excepciones Preliminares, Fondo, Reparaciones y Costas. Sentencia de 2 de julio de 2004, Serie C No 107, párrafo 167.

13 Comisión Interamericana de Derechos Humanos, Informe No 55/97. Abella y Otros vs. Argentina, Caso 11.137, párrafo 262.

14 El recurso debe ser ordinario y debe tener como lógica (y necesaria) conexión el derecho de toda persona "a disponer, en un plazo razonable y por escrito, de los fallos en los que se determine su responsabilidad, debidamente motivados, a efectos de su posible apelación”. Agrega el autor: “[...] en caso contrario, no se estaría concediendo la debida revisión de la sentencia, ni acceso oportuno a las razones del fallo, impidiéndose ejercer eficazmente el derecho de defensa. Esto implica asimismo que las resoluciones que se emitan en distintas instancias deben contener, con exactitud y claridad, las razones por las cuales se llega a la conclusión que ellas contienen, la valoración de las pruebas y los fundamentos jurídicos y normativos en que se basa”. HuERTA (2003), p. 58.

15 Corte IDH, Caso Herrera Ulloa vs. Costa Rica. Excepciones Preliminares, Fondo, Reparaciones y Costas. Sentencia de 2 de julio de 2004, Serie C No 107, párrafo 161; Corte IDH, Caso Mohamed Vs. Argentina. Excepción Preliminar, Fondo, Reparaciones y Costas. Sentencia de 23 noviembre de 2012, Serie C No 255, párrafo 99.

16 Corte IDH, Caso Mohamed vs. Argentina. Excepción Preliminar, Fondo, Reparaciones y Costas. Sentencia de 23 noviembre de 2012, Serie C No 255, párrafo 99; Corte IDH, Caso Herrera Ulloa vs. Costa Rica. Excepciones Preliminares, Fondo, Reparaciones y Costas. Sentencia de 2 de julio de 2004, Serie C No 107, párrafo 161.

17 Corte IDH, Caso Mohamed vs. Argentina. Excepción Preliminar, Fondo, Reparaciones y Costas. Sentencia de 23 noviembre de 2012, Serie C No 255, párrafo 99; Corte IDH, Caso Herrera Ulloa vs. Costa Rica. Excepciones Preliminares, Fondo, Reparaciones y Costas. Sentencia de 2 de julio de 2004, Serie C No 107, párrafo 164. 
i. Al momento de producirse el agravio: "Teniendo en cuenta que las garantías judiciales buscan que quien esté incurso en un proceso no sea sometido a decisiones arbitrarias, la Corte interpreta que el derecho a recurrir del fallo no podría ser efectivo si no se garantiza respecto de todo aquel que es condenado, ya que la condena es la manifestación del ejercicio del poder punitivo del Estado. Resulta contrario al propósito de ese derecho especifico que no sea garantizado frente a quien es condenado mediante una sentencia que revoca una decisión absolutoria. Interpretar lo contrario, implicaría dejar al condenado desprovisto de un recurso contra la condena. Se trata de una garantía del individuo frente al Estado y no solamente una guía que orienta el diseño de los sistemas de impugnación en los ordenamientos jurídicos de los Estados Partes de la Convención"18, y

ii. Antes de que la sentencia adquiera la autoridad de cosa juzgada: "El derecho de interponer un recurso contra el fallo debe ser garantizado antes de que la sentencia adquiera calidad de cosa juzgada"19, ya que lo que se busca es "proteger el derecho de defensa otorgando durante el proceso la posibilidad de interponer un recurso para evitar que quede firme una decisión que fue adoptada con vicios y que contiene errores que ocasionarán un perjuicio indebido a los intereses de una persona"20.

De esta manera, lo que asegura el derecho al recurso es la posibilidad de impugnar una sentencia agraviante, por medio de un recurso ordinario, sencillo, eficaz y accesible, ante un órgano superior, igualmente independiente e imparcial, que permita una revisión amplia de las cuestiones fácticas, probatorias y jurídicas, debatidas y analizadas, ante el juez a quo.

\section{El recurso de casación}

Tradicionalmente los recursos procesales se han clasificado en arbitrios ordinarios y extraordinarios. Los primeros son aquellos que la ley concede comúnmente y respecto de la generalidad de las resoluciones judiciales, es decir, serían la regla general; por su parte, los recursos extraordinarios serían aquellos que proceden respecto de determinadas resoluciones y solo por alguna de las causales taxativas establecidas en la ley, en consecuencia, serían la excepción.

18 Corte IDH, Caso Mohamed vs. Argentina. Excepción Preliminar, Fondo, Reparaciones y Costas. Sentencia de 23 noviembre de 2012, Serie C No 255, párrafo 92.

19 Corte IDH, Caso Herrera Ulloa vs. Costa Rica. Excepciones Preliminares, Fondo, Reparaciones y Costas. Sentencia de 2 de julio de 2004, Serie C No 107, párrafo 158.

20 Corte IDH, Caso Herrera Ulloa vs. Costa Rica. Excepciones Preliminares, Fondo, Reparaciones y Costas. Sentencia de 2 de julio de 2004, Serie C No 107, párrafo 158. 
Dicha distinción es determinante, porque lo que garantiza el derecho al recurso es la existencia de un arbitrio ordinario. De esta manera, la Corte Interamericana ha fallado que,

"De acuerdo al objeto y fin de la Convención Americana, cual es la eficaz protección de los derechos humanos, se debe entender que el recurso que contempla el artículo 8.2.h. de dicho tratado debe ser un recurso ordinario eficaz mediante el cual un juez o tribunal superior procure la corrección de decisiones jurisdiccionales contrarias al derecho" 21 .

Asimismo, tradicionalmente se suelen diferenciar los medios de impugnación ordinarios y extraordinarios por las siguientes consideraciones:

“i. Los recursos ordinarios permiten obtener la modificación o el reemplazo de una resolución judicial por cualquier vicio de que ella adolezca; los recursos extraordinarios solo lo permiten cuando se basan en alguno o algunos de los defectos o vicios prescritos expresamente en la ley;

ii. El juez que conoce de un recurso ordinario tiene las mismas facultades que el que dictó la resolución que recurre; el juez que conoce de un recurso extraordinario tiene limitadas sus facultades en virtud de la naturaleza misma de la investigación que la ley le encomienda, y

iii. Los recursos ordinarios suspenden la ejecución de la sentencia recurrida, salvo que se trate de sentencias que causen ejecutoria, es decir, aquellas que por expresa disposición de la ley pueden cumplirse no obstante la interposición del recurso; los recursos extraordinarios no suspenden la ejecución de los fallos, salvo los casos excepcionales determinados por la ley"22.

En dicho marco, toca referirse a la naturaleza del recurso de casación que, como tal, es un medio de impugnación extraordinario, dado que procede respecto de determinadas resoluciones judiciales y por alguna de las causales establecidas en la ley. Asimismo, al constatar el origen de este recurso, queda de manifiesto que su función original es más bien extraprocesal, jamás concebido como un mecanismo de protección y defensa del ciudadano (garantía) frente al Estado-juez, como veremos a continuación.

El recurso de casación constituye el remedio procesal de nulidad típico, que surgió como garantía para la correcta aplicación e interpretación del Derecho material, es

21 Corte IDH, Caso Herrera Ulloa vs. Costa Rica. Excepciones Preliminares, Fondo, Reparaciones y Costas. Sentencia de 2 de julio de 2004, Serie C No 107, párrafo 161.

22 Espinosa (1980), p. 3. 
decir, actúa como un medio que permite la unificación de la jurisprudencia y mantener incólume la voluntad del legislador expresada en la ley, como manifestación de los principios de seguridad jurídica y de igualdad de trato ${ }^{23}$. Comúnmente se define a la casación como aquel recurso "que tiene por objeto obtener la invalidación o anulación de una sentencia en los casos expresamente señalados por la ley" 24 , conforme al artículo 764 del Código de Procedimiento Civil. Asimismo, es importante destacar que etimológicamente la palabra "casación" proviene de la forma verbal latina cassare, "que significa casar, abrogar, derogar, anular o deshacer" 25 , generando un mero sistema de control de legalidad, "estándole por ende excluida la indagación sobre el mérito (fondo de lo controvertido en ese particular litigio o causa)" 26 .

La casación busca la anulación de una sentencia por vicios jurídicos en la sustanciación del proceso o en la dictación de la sentencia, es decir, por vicios in procedendo y vicios in iudicando ${ }^{27}$. Ahora bien, en cuanto a los fines que se le suelen atribuir a este recurso procesal está, en primer término, su fin político o extraprocesal, "como vehículo necesario para el control de la interpretación jurídica y la aplicación uniforme del derecho objetivo" 28 , por ello y como complemento se le entrega su resolución -por regla general- a un único tribunal superior y que se encuentra en la cúspide del sistema de administración de justicia. Luego, en el devenir de los años a la casación se le atribuyó también otro fin u objeto, ligado al justiciable, como "medio de impugnación para lograr la eliminación de una sentencia jurídicamente errónea que lo perjudica (finalidad procesal de la casación)" 29 , con todo, "la concesión de un recurso al afectado solo era la forma de conseguir, en la práctica, la neutralización de la rebeldía de quienes cumplían las funciones judiciales pudiera ser realizada, pero no había en esto indicio alguno de un derecho subjetivo del agraviado a contar con un recurso contra las decisiones judiciales que lo afectaban, de allí que este medio de impugnación pudiera ser soberanamente limitado en sus alcances revisorios" 30 .

\footnotetext{
23 Valenzuela (2015), p. 23.

24 Casarino (2009), p. 130.

25 Espinosa (1980), p. 87.

26 Morello (1993), pp. 9-10.

27 Valenzuela (2015), p. 23.

28 PAstor (2001), pp. 13-14.

29 PAstor (2001), p. 12.

30 Pastor (2001), p. 27.
} 
El fin político de la casación se remonta a su origen mismo, esto es, la Revolución Francesa, donde surge como un instituto complementario para defender la soberanía popular expresada en el producto normativo del legislador: la ley. De esta manera, la función principal de este arbitrio está dada por la nomofiláctica o función de protección de la misma. Por ello se estableció la distinción entre cuestiones de hecho y cuestiones de derecho, limitándose la casación a estas últimas, mas no a cualquier error iuris, sino que a errores de tal entidad que generaban un problema político, desconociendo la voluntad contenida en la legislación ${ }^{31}$, "lo que supone una reacción más enérgica de la ley frente a la rebelión del juez"32.

En otra línea, cabe señalar que la casación en su origen contemplaba solo dos componentes: de una parte, la concesión del recurso cuando existiese violación de ley (vitium iuris), y la existencia de un órgano jurisdiccional llamado a corregir dicho apartamiento de la ley. Posteriormente, se le agregó un tercer componente para proceder ahora a la unificación de la interpretación judicial, como fin político extraprocesal también ${ }^{33}$. Así, "la casación era el mejor apoyo externo a las propuestas que llevaban a los legisladores a sancionar una ley que en su despliegue práctico -aplicación - no debía ser desvirtuada o deformada por interpretaciones judiciales o eventuales precisiones doctrinarias" 34 .

De esta manera, se fue perfilando el recurso de casación que fue acogido en nuestro sistema jurídico, heredero de la tradición legalista francesa, que se ve claramente expresada en el artículo $1^{\circ}$ del Código Civil. En dicha línea, no cabe si no señalar que este recurso busca una correcta aplicación e interpretación de la ley, constituyéndose en una verdadera garantía del ordenamiento jurídico, mas, y solo en forma indirecta, lo podemos considerar como una garantía del justiciable para la obtención de una sentencia justa y correcta, ya que dichas finalidades no están concebidas en su creación original. Clarifica la idea anterior el hecho que en la Francia ilustrada existiere tal desconfianza en los jueces, bajo la premisa tradicional que entendía al juez como la "boca de la ley", es decir, mero aplicador al caso concreto, no pudiendo interpretar o modificarla, debiendo ceñirse lo más posible a su letra (voluntad soberana) ${ }^{35}$.

\footnotetext{
31 Valenzuela (2015), p. 24.

32 Pastor (2001), p. 18.

33 Valenzuela (2015), p. 24.

34 Morello (1993), p. 9.

35 Valenzuela (2015), p. 25.
} 
En dicha línea hay que distinguir, entonces, dos situaciones:

i. Cuando el legislador procesal establece solo el acceso a la vía impugnaticia extraordinaria, $y$

ii. Cuando se permite el acceso a la vía extraordinaria, una vez resuelto el recurso ordinario.

De esta forma, hemos dicho "que el carácter ordinario o extraordinario del recurso incide de manera diversa sobre el acceso a la tutela judicial efectiva mediante el recurso. Así, cuando el sistema permite que conjuntamente con el recurso ordinario (apelación), se pueda acceder a otra instancia procesal ad quem mediante el recurso extraordinario, resulta clara que la tutela judicial será más determinante. Sin embargo, cuando el sistema impone que se pase directamente a la vía recursiva extraordinaria, sin autorizar el acceso previo a la vía recursiva ordinaria, el logro de la tutela judicial resulta menos incisiva" 36 .

De esta forma, se debe señalar que la existencia de recursos de derecho estricto no atenta contra las garantías del derecho al recurso, en la medida que se expresen como arbitrios extraordinarios disponibles contra la respuesta jurisdiccional, ya revisada: confirmada, revocada, modificada o sustituida, por el superior jerárquico del tribunal que la resolvió en primer grado de jurisdicción, en dicha medida, dichos recursos nada vienen a añadir al derecho a recurrir del justiciable, toda vez que su objetivo trasciende a la mera pretensión particular del recurrente, ya que estos solo persiguen una adecuada y homogénea interpretación y aplicación del Derecho material, en aras de proteger la ley sancionada por el legislador.

En síntesis, el acceso a un recurso extraordinario no está garantizado ni constitucional ni convencionalmente, correspondiendo determinar su establecimiento, procedencia y formalidades al legislador, ya que no se trata de un elemento esencial del debido proceso. De esta manera, cabe ya señalar que no existe un derecho a la casación, a la apelación ni a un recurso determinado, sino lo que asegura el debido proceso es la existencia de un arbitrio procesal ordinario, que permita una revisión integral de la respuesta jurisdiccional.

\section{Argumentos de los fallos comentados}

Ambos fallos fijan como objeto de la cuestión de inaplicabilidad que es competencia del Tribunal "pronunciarse acerca de la excepción que la ley adjetiva civil hace en este tipo de contenciosos, en cuya virtud a los justiciables se les niega el acceso

36 Palomo y Valenzuela (2011), p. 405. 
a un recurso de casación, amén de no concederles una equivalente vía de impugnación en su reemplazo".

En efecto, el Tribunal Constitucional contrasta la excepción contenida en el artículo 768 del Código de Procedimiento Civil con la Constitución Política. En dicha línea, creemos errada la determinación de los votos de mayoría, ya que-como se estableció anteriormente- el acceso a la vía extraordinaria no forma parte de las garantías que asegura el debido proceso constitucional. De esta manera, tanto la sentencia definitiva del juicio especial de arrendamiento como la del proceso de reclamación tributaria son susceptibles de ser impugnadas por medio del recurso, en este caso el de apelación, que constituye el arbitrio ordinario típico que permite revisar la respuesta jurisdiccional en toda su extensión.

Ahora bien, dado que la inaplicabilidad constituye un enjuiciamiento concreto de constitucionalidad de los preceptos legales impugnados, ambos fallos obviaron la existencia de normas especiales que -incluso- amplían el alcance ordinario del recurso de apelación.

El Código Tributario prescribe en su artículo 140:

"En contra de la sentencia de primera instancia no procederá el recurso de casación en la forma ni su anulación de oficio. Los vicios en que se hubiere incurrido deberán ser corregidos por el Tribunal de Apelaciones que corresponda".

Por su parte, el artículo $8^{\circ}$, en el inciso tercero del numeral 9o, de la ley No 18.101 señala:

"En segunda instancia, podrá el tribunal de alzada, a solicitud de parte, pronunciarse por vía de apelación sobre todas las cuestiones que se hayan debatido en primera para ser falladas en definitiva, aun cuando no hayan sido resueltas en el fallo apelado".

De esta manera, ambos procedimientos especiales satisfacen el estándar impuesto por el derecho al recurso:

i. Existencia de un recurso,

ii. El recurso es ordinario, y

iii. El recurso permite la revisión de la respuesta jurisdiccional en toda su extensión.

Distinta es la situación de que se quiera censurar dichos procedimientos por no contemplar la entrada a una fase de revisión extraordinaria, cuestión que, como dijimos, corresponde a opciones de técnica legislativa, siendo el Tribunal -en estos casos- poco deferente con el legislador, creando un recurso inexistente y ampliando artificiosamente las garantías del derecho a impugnar las resoluciones judiciales. 
En síntesis, los fallos se fundan en la infracción de la igualdad ante la ley y el debido proceso, ante la inexistencia -para los casos concretos- de un recurso anulatorio efectivo, lo que permite dejar sin control algunas de las infracciones por las que procede el recurso de casación. Para ello, señalan que no se vislumbra una finalidad intrínsecamente legítima en el establecimiento de la excepción censurada y esta no se condice con el mandato que le asiste al legislador de allanar el acceso a un recurso útil, precisando que no están creando un recurso inexistente, puesto que al eliminarse una excepción solo retoma vigencia la regla general.

Por su lado, los votos de minoría parten por establecer que acoger un recurso de inaplicabilidad no puede significar nunca la concesión de un recurso procesal determinado, decisión que le compete al legislador. Concluyen que la norma no vulnera el derecho a la igualdad ante la ley, porque es una facultad del legislador establecer que una u otra causal de la casación en la forma no sea procedente respecto de determinados procedimientos, además, la excepción opera en todo procedimiento especial y respecto de todas las partes y que, en cada caso, existen mecanismos que permiten un control amplio por parte del tribunal ad quem, y que no se vulnera el debido proceso, toda vez que no existe un derecho a la casación y que el derecho al recurso no significa derecho a un recurso concreto.

En consecuencia, compartiendo -en su mayoría- los argumentos esgrimidos en los votos disidentes, se debe señalar que el artículo 768 del Código de Procedimiento Civil, en concreto y abstracto, conforme a la Constitución y al derecho internacional de los derechos humanos, no vulnera el derecho a la igualdad ante la ley ni la igual protección de la ley en el ejercicio de los derechos.

Finalmente, es de destacar que el Tribunal Constitucional -en los hechosmodifica el efecto negativo, propio de la acción de inaplicabilidad, al conceder un recurso procesal respecto de procesos no considerados en la legislación vigente, modificando de facto la sustanciación de los mismos, lo que claramente contraviene sus facultades y atribuciones constitucionales.

\section{E. Derecho al recurso en la oscilante jurisprudencia del Tribunal Constitucional}

Como dijimos, el Tribunal Constitucional ha reconocido la existencia del derecho al recurso como una de las garantías que integran el debido proceso constitucional. En efecto, ha sentenciado:

"Que, no obstante lo anterior y entrando al fondo del asunto, cabe sostener, en primer lugar, que el derecho al recurso forma parte integrante del derecho al debido proceso. 
Asi se ha señalado, entre otras sentencias, en los roles $N^{o}$. 376, 389, 478, 481, 821, 934 y 986. De este modo, se ha dicho expresamente que él derecho a un proceso previo, legalmente tramitado, racional y justo, que la Constitución asegura a todas las personas, debe contemplar las siguientes garantías: la publicidad de los actos jurisdiccionales, el derecho a la acción, el oportuno conocimiento de ella por la parte contraria, el emplazamiento, adecuada defensa y asesoría con abogados, la producción libre de pruebas conforme a la ley, el examen y objeción de la evidencia rendida, la bilateralidad de la audiencia, la facultad de interponer recursos para revisar las sentencias dictadas por tribunales inferiores..."'37.

Por su parte, de la jurisprudencia tradicional del Tribunal podemos determinar los siguientes criterios sobre la materia ${ }^{38}$ :

i. Que si bien nuestra Carta Fundamental exige un debido proceso que consagre la revisión de las sentencias, ello no significa que se deba consagrar el derecho a la doble instancia, ya que la doble o única instancia constituirían opciones de política legislativa, que corresponde exclusivamente al legislador decidir ${ }^{39}$;

ii. Que el derecho al recurso no es sinónimo de derecho al recurso de apelación ${ }^{40}, y$

iii. Particularmente sobre el sistema recursivo procesal penal, ha sentenciado que el recurso de nulidad no puede juzgarse utilizando como parámetro el recurso de apelación ${ }^{41}$ y que no se vulnera el derecho a la defensa, dado que el recurso tiene como una de sus causales la violación de derechos fundamentales ${ }^{42}$.

Asimismo, el Tribunal Constitucional ha fallado otras materias en base al derecho al recurso, como es el caso de la apelación del auto de apertura de juicio oral en materia procesal penal. Sobre el particular -al igual que en la presente materia- ha existido una oscilante jurisprudencia, procediéndose en 2010 a acoger dos requerimientos, situación que se ha revertido en el último tiempo.

Finalmente, el Tribunal Constitucional ha rechazado dos requerimientos que censuraban el citado artículo 768 del Código de Procedimiento Civil: en 2012,

37 Tribunal Constitucional, Rol No 1432 , de 5 de agosto de 2010, considerando $12^{\circ}$.

38 Valenzuela (2015), pp. 54-62.

39 Tribunal Constitucional, Rol No 1432, de 5 de agosto de 2010, considerado $14^{\circ}$ y Rol No 986, de 30 de enero de 2008 , considerando $26^{\circ}$.

40 Tribunal Constitucional, Rol No 1432, de 5 de agosto de 2010, considerando $19^{\circ}$.

41 Tribunal Constitucional, Rol No 1432, de 5 de agosto de 2010, considerando $17^{\circ}$.

42 Tribunal Constitucional, Rol No 1432, de 5 de agosto de 2010, considerando $20^{\circ}$. 
por empate de votos, en el proceso Rol No 2034-2011, y en 2013, por mayoría, en el proceso Rol No 2137-2011.

\section{CONCLUSIONeS}

Podemos cerrar señalando que:

i. El derecho al recurso forma parte de las garantías del debido proceso;

ii. Dicho derecho comprende la posibilidad de impugnar las resoluciones judiciales agraviantes por medio de un recurso ordinario, sencillo, eficaz y accesible, que posibilite un control amplio de la respuesta jurisdiccional;

iii. No forma parte de las garantías del derecho al recurso el acceso a una vía extraordinaria de control respecto de una sentencia ya revisada. El establecimiento de dicha posibilidad corresponde a opciones de técnica legislativa, ya que no forma parte de las piezas esenciales que protege y garantiza el debido proceso constitucional;

iv. La incidencia de la tutela jurisdiccional depende de la naturaleza del arbitrio que tenga disponible el justiciable. De esta manera, lo que resguarda el derecho al recurso es la posibilidad de impugnar la respuesta jurisdiccional por medio de un recurso ordinario, que permita abrir y entrar a una -necesaria- segunda instancia, en la medida que el fallo le sea agraviante, y

v. No existe un derecho a la casación, a la apelación ni a un recurso determinado. En efecto, solo forma parte del debido proceso la existencia de un medio de impugnación que cumpla los requisitos antes enunciados, siendo indiferente el nombre que se le atribuya, conforme se expresó.

\section{BiBLIOGRAFÍA CITADA}

Casarino Viterbo, Mario (2009): Manual de Derecho Procesal. Derecho Procesal Civil (Santiago de Chile, tomo IV, Ed. Jurídica de Chile).

Espinosa Solís de Ovando, Alejando (1985): De los recursos procesales en el Código de Procedimiento Civil (Santiago de Chile, 6a ed., Ed. Jurídica de Chile).

GonzÁlez Pérez, Manuel (1989): El derecho a la tutela jurisdiccional (Madrid, $2^{\text {a }}$ ed., Editorial Civita).

Huerta Guerrero, Luis (2003): El debido proceso en las decisiones de la Corte Interamericana de Derechos Humanos (Lima, Comisión Andina de Juristas).

Morello, Agusto M. (1993): La casación. Un modelo intermedio eficiente (Buenos Aires, Abeledo-Perrot).

Nogueira Alcalá, Humberto (2008): Derechos fundamentales y garantías constitucionales (Santiago de Chile, tomo 2, CECOCH, Ed. Librotecnia). 
Palomo Vélez, Diego; Valenzuela Villalobos, Williams (2011): “Declaraciones de inadmisibilidad del recurso de nulidad laboral como restricción indebida al derecho al recurso: Jurisprudencia correctiva de la E. Corte Suprema”, en Revista de Derecho Universidad Católica del Norte (Vol. 18, No 2).

Pastor, Daniel R. (2001): La nueva imagen de la casación penal (Buenos Aires, Ed. Ad-Hoc).

Valenzuela Villalobos, Williams E. (2015): Derecho al recurso. Desde el sistema interamericano a la situación de Chile (México, Ed. Porrúa). 